\title{
VÍDEO E STORYTELLING NUM MUNDO DIGITAL: INTERAÇÕES E NARRATIVAS EM VIDEOCLIPES
}

\author{
Rodrigo Oliva, José Bidarra \& Denize Araújo
}

\begin{abstract}
Resumo
Este artigo apresenta um estudo sobre as narrativas em videoclipes. Discute-se os arranjos das linguagens audiovisuais a partir de configurações estabelecidas por características dos meios de comunicação, enfatizando o papel das plataformas de difusão de informação e entretenimento como o YouTube. Sublinha-se ainda um diálogo com a linguagem do cinema e evidencia-se que, nos cenários contemporâneos, os videoclipes contam histórias. Discute-se que os videoclipes contemporâneos, em grande maioria, prolongam o tempo da música, com pausas, atuações de personagens, inserção de diálogos e outros elementos estruturantes que descaracterizam os paradigmas clássicos e convencionais da linguagem. Para a análise, o objeto do estudo são os videoclipes do cineasta canadense Xavier Dolan. A fundamentação teórica é estabelecida a partir de autores inseridos nos debates da cultura da convergência, de transmídia storytelling e das interações entre linguagens audiovisuais.
\end{abstract}

\section{Palavras-Chave}

Cinema; videoclipes; narrativa; storytelling; transmídia

\begin{abstract}
This paper presents a study about narratives in music videos. It discusses the arrangements of audio-visual languages from settings established by characteristics of the media, emphasizing the role of platforms for the diffusion of information and entertainment such as YouTube. It highlights a dialogue within cinema's own language and shows that, in contemporary scenarios, music videos actually tell stories. It is argued that contemporary music videos, in great majority, increase the duration of music, with pauses, performances of characters, insertion of dialogues and other structuring elements that are not typical of the classic and conventional paradigms of a language. For our purposes, the objects of this study are the music videos of Canadian filmmaker Xavier Dolan. The theoretical foundation is established through authors involved in debates around a culture of convergence, transmedia storytelling and interactions among the audio-visual languages.
\end{abstract}




\section{INTRODUÇÃo}

Está sendo possível verificar algumas transformações nas formas de comunicação nestes últimos anos. Estamos acompanhando o desenrolar de novos arranjos em perspectivas remodeladas nos tradicionais meios de comunicação e o surgimento de novas tecnologias da comunicação que estão permitindo que se reconfigurem processos de interação entre emissores e receptores. Essas novas dinâmicas promovem, no âmbito das linguagens, reconfigurações nos processos estéticos, sociais e poéticos das mensagens e suas articulações na forma como os discursos são montados e projetados (Oliva, 2015).

Neste cenário da cultura da convergência, debatido por Henry Jenkins (2014), a propagabilidade torna-se evidente, pois cria-se um ambiente onde a interatividade e a participação individual são as referências mais marcantes. Segundo Jenkins, a propagabilidade relaciona-se aos deslocamentos de conteúdo, ou seja, aos modelos de aderência que circulam por meio da interatividade entre as pessoas envolvidas no processo de comunicação. Contudo, foi possível perceber que a propagabilidade se diferencia do antigo status da comunicação que se atinha a projeção de conteúdo em plataformas únicas para públicos amplos, discutidos por Jenkins a partir do conceito de aderência do pesquisador Malcolm Gladwell.

A aderência privilegia a colocação do conteúdo em um único lugar e procura levar a audiência até lá para que possa ser computada. Essa visualização do destino muitas vezes entra em conflito tanto com a experiência da navegação dinâmica de usuários individuais da internet como, o que é mais importante, atrito com a circulação de conteúdo por meio de conexões sociais dos membros da audiência. (Jenkins, 2014, p. 28)

Jenkins estabelece uma análise comparativa sobre esses dois momentos que, vistos de uma maneira isolada, permitem uma reflexão sobre o atual momento da comunicação, já que os elementos estruturais de um processo comunicacional tendem a se movimentar. Ao se inserirem socialmente, as novas mídias traçaram novos caminhos para o desenvolvimento das relações entre indivíduos e os meios, desenhando novos alicerces e promovendo aberturas para reinvenções nos processos de criação das mensagens (Sousa, Zagalo \& Martins, 2012). Na contemporaneidade, a participação da recepção configura novas artimanhas, pois as contribuições espontâneas das pessoas interferem na construção das novas narrativas (Brandão, 2010).

Raymond Bellour (1997), em seu livro clássico Entre Imagens, introduz considerações sobre um momento das artes visuais e sonoras, onde elementos constituintes e característicos de uma linguagem são incorporados em outros, como se o vídeo fosse incorporado a um filme de película ou uma imagem fixa fotográfica a um filme. Esse caráter de hibridização é algo comum nos contornos midiáticos atuais. Tendo em vista uma discussão que será estabelecida neste trabalho, sobre a construção das mensagens a partir destas novas tecnologias, gostaríamos de estabelecer um diálogo com este autor, pois o mesmo discute uma relação entre o espectador de fotografia e o de cinema. A 
partir desta teoria, procuramos problematizar como se estabelecem essas relações nas experiências com as produções de vídeos projetados em plataformas como o YouTube.

Para Bellour, o espectador de cinema é ágil, tem pouco tempo para a contemplação, é quase impossível fechar os olhos, pois o produto fílmico pode ser perdido com um simples piscar de olhos. Diferentemente da contemplação fotográfica, onde o olhar tende a caminhar pelos contornos e centro do enquadramento, a fotografia demanda uma forma de contemplação.

O espectador de cinema, esse desocupado, é um ser apressado. Ele segue um filme que às vezes pode lhe parecer muito lento, mas que com toda a certeza se tornará rápido demais se nele tentar se deter. Será que no cinema eu acrescento algo à imagem? - não creio; não tenho tempo; diante da tela, não sou livre para fechar os olhos; se não, ao abri-los, não encontrarei mais a mesma imagem. Diante de uma fotografia, ao contrário, quase sempre fechamos mais ou menos os olhos: o tempo (teoricamente infinito e que, principalmente, pode ser repetido) de produzir o complemento graças ao qual aquele que vê a imagem consegue situar-se nela. (Bellour, 1997, p. 84)

Verificamos uma questão importante a partir do pensamento de Bellour: o olhar que se estabelece para as formas cinema e fotografia, apesar da natureza muito próxima destas artes, é de categorias diferentes. Essa relação pode ser estabelecida por uma atuação maior de quem olha para as formas da natureza fotográfica do que para a cinematográfica.

As novas mídias produzirão novos contornos para este diálogo. Segundo Justin Wolske (2014, p. 203), o consumo de produtos midiáticos televisivos, ainda hegemônico, vem perdendo espaço para um acelerado avanço de audiências em ambientes online. Em se tratando de consumo de vídeos, portanto, esse salto é maior, tendo em vista que existe atualmente uma procura por consumos de materiais audiovisuais curtos e rápidos. Segundo Wolske (2014, p. 203), dois são os fatores principais deste novo contexto. Primeiramente, a capacidade de ver em qualquer momento os conteúdos de vídeo online e segundo uma espécie de criação voltada para conteúdos mais curtos, com pouca complexidade e pouco profissionalismo. O consumo em dispositivos móveis, por exemplo, altera a experiência audiovisual, pois com as pequenas telas, os detalhes passam despercebidos. As imagens são apresentadas com pouca nitidez e qualidade fotográfica, diminuindo o impacto das cenas com perspectiva, pois altera a profundidade de campo. Percebe-se, também, que performance de atores bem como recursos audiovisuais são pouco apreendidos pelos consumidores.

Neste trabalho, buscamos apresentar algumas caracterizações deste novo contexto da comunicação audiovisual. O foco do estudo será a linguagem do videoclipe e sua articulação com a linguagem do cinema. Estabelecemos algumas considerações sobre as dinâmicas que envolvem as narrativas, buscando compreender uma complexidade, pois um dos centros desta discussão se atém a uma específica consideração sobre uma abertura para videoclipes que contam histórias. Verificamos uma tendência que vai na 
contramão dos vídeos de natureza rápida e curta, mas que em determinadas produções prolonga o tempo da música, com pausas, atuações de personagens, inserção de diálogos e outros elementos estruturantes da linguagem que descaracterizam os paradigmas clássicos e convencionais do videoclipe.

A pesquisadora norte americana Carol Vernalis vem traduzindo esta dinâmica da linguagem do videoclipe nos novos cenários. A autora discute isso de maneira a apontar quais as lógicas que estão por trás destes novos cenários. Vernalis (2004) aponta que o formato dos videoclipes é bastante fluído. A partir do tempo numérico exato das canções, as narrativas em videoclipes não se completam. Essa dinâmica é evidenciada, considerando que os filmes se traduzem em variadas possibilidades de articulação de linguagem, como performances dos cantores inseridos na imagem audiovisual, ausência de personagens, ausência de diálogos e incrustações diversas, tendo em vista que o mais característico da linguagem do videoclipe é a sua natureza híbrida. Defendemos que esta dinâmica proposta pela autora se atém ao cenário de consumo dos videoclipes propagados pelo canal MTV.

Com o surgimento da internet e os caminhos apontados pela propagabilidade, nota-se uma certa autonomia não somente de quem recebe as mensagens, mas também de quem as produz. Um videoclipe não necessariamente necessita estar preso ao tempo total da música e nem ao formato que obedece aos alicerces da projeção clássica televisiva, pois esta é emoldurada em blocos bem definidos, estruturados pelo formato da publicidade. De certa forma, a MTV implementou um modelo de construção para o formato, apontado nos cânones da publicidade, em similaridade com os procedimentos do rádio, como se fosse uma rádio com imagens.

Neste contexto, apresentamos um debate sobre o conceito de storytelling, enfatizando a importância do entendimento de como a prática de se contar histórias se torna mais evidente no universo do videoclipe e da publicidade atualmente. Pensamos que a prática da experimentação, muito divulgada pela videoarte, se distanciava das questões narrativas. Inicialmente, o que caracterizou o videoclipe foi justamente essa natureza de aproximação com a experimentação. Ou seja, as narrativas em videoclipes tendem a se ampliarem nestes novos cenários. Estas considerações podem ser estudadas a partir da obra: The New Digital Storytelling, de Bryan Alexander (2011).

Em seguida, discutimos algumas considerações sobre a plataforma YouTube, pois sua natureza de projeção abriu possibilidades de criações infinitas. O papel social do YouTube caracterizado pelo armazenamento, projeção e recuperação histórica do audiovisual é impactante. Neste sentido, é importante pensar como a natureza da plataforma permite que as narrativas se estruturem nos materiais audiovisuais.

Estabelecemos ainda uma discussão em volta do conceito que representa estes novos cenários, chamado de narrativas dilatadas (Oliva, 2017, p. 110), que aproxima as linguagens do cinema e do videoclipe, e traduz um pensamento sobre como se articulam as narrativas em produção audiovisuais contemporâneas como os clipes que hoje são feitos para serem fruídos via internet. Esclarecemos que as narrativas se tornam uma expressão para usufruir em tempos cada vez mais rápidos, com imagens mostrando 
grandes planos das personagens e pormenores de objetos, seguindo uma trama pouco desenvolvida, e com um tratamento de cores saturadas ou alto contraste, tudo isto para manter a atenção do espectador que usa telas de pequeno tamanho.

Transpomos para os estudos da linguagem do videoclipe. Em novos ambientes online, verificamos que os videoclipes tendem à ampliação narrativa em nível temporal e espacial, quer pelo tempo total ou não da música. Para a discussão deste conceito, analisamos dois videoclipes do cineasta canadense Xavier Dolan, ambos contemporâneos, que traduzem as considerações apontadas neste projeto. O primeiro chama-se College Boy, foi produzido para a banda francesa Indochine, no ano de 2013. Este videoclipe é feito totalmente sem a presença do grupo musical e possui uma narrativa linear bem amarrada, com fatos, personagens, ações e imagens impactantes. O segundo videoclipe foi dirigido para a divulgação da música Hello, da cantora pop inglesa Adele. Neste, a inserção de diálogos em background, ou seja, mixado num volume menor com música tema, é um recurso usado na narrativa do filme. A atuação da personagem principal do videoclipe é feita pela própria cantora, ora atuando como atriz ora como intérprete.

Finalizamos esta introdução com a reflexão de que a convergência das linguagens nestes últimos tempos atesta um caráter fluído e de intensa hibridização. Acreditamos ser importante tal justificativa, pois vemos muito mais um cenário de reconfigurações e de remodelações do que mudanças de paradigmas. Acreditamos que, nos cenários contemporâneos, a linguagem do videoclipe e a do cinema estabelecem um fluxo de conexões que operam recriações estéticas e formais evidentes.

\section{STORYTELLING, NARRATIVAS E VIDEOCLIPES}

O conceito de storytelling vem sendo amplamente discutido, principalmente na associação com as novas tecnologias. Entretanto, contar histórias é uma atividade recorrente na humanidade. Desde a Antiguidade, na tradição oral e na escrita, acompanhamos o desenrolar de narrativas. É interessante perceber como as narrativas, em tempos atuais, se espalham nos novos formatos. Esse caráter fluido, uma espécie de derramamento, que estabelece um diálogo importante com as novas tecnologias.

Hoje assiste-se ao renascimento global de um modelo designado como digital storytelling, que poderia ser traduzido como "narrativas digitais", e neste caso não se trata de uma moda; as histórias e narrativas têm sido usadas no ensino e aprendizagem desde há muito, mas, também em áreas como a gestão, a psicologia ou a saúde. As histórias ajudam-nos a compreender a experiência individual e a criar uma percepção do mundo que nos rodeia. As histórias também ajudam a construir ligações com o conhecimento adquirido e a melhorar a memória, como resultado, as boas histórias são melhor lembradas pelos alunos do que as aulas regulares. Por outro lado, dado o papel central da narrativa no nosso quotidiano e a explosão tecnológica durante estas últimas décadas, não é surpreendente encontrar narrativas digitais como estratégias pedagógicas em muitos cursos universitários, tal como são essenciais para o teatro, os filmes e os jogos.

Mas o que são "narrativas digitais"? Essencialmente, referimo-nos a artefatos digitais que incluem: uma narração convincente de uma história; um contexto significativo 
para a compreensão da história; texto, imagens e gráficos que capturam ou expandem as emoções encontradas na narrativa; voz, música e efeitos sonoros que reforçam temas; e mecanismos que convidam à reflexão e envolvimento do público-alvo.

As narrativas referem-se a uma série de eventos que aconteceram (no passado, como uma memória), estão a acontecer (no presente) ou vão acontecer (no futuro). Por seu turno, contar histórias implica integrar quatro elementos clássicos que são ainda válidos na era digital, ou seja: uma trama; um narrador; um contexto; as personagens.

De uma forma simples, poderíamos dizer que uma narrativa digital é aquela narrativa que está suportada em meios digitais. Atualmente esta expressão abrange um conjunto grande de projetos e de produtos que podem incluir: livros de recortes e fotografias (scrapbooks), portefólios, peças de radiodifusão (podcasts), projetos multimídia e vídeos. As ferramentas digitais postas ao alcance de qualquer um, como parte do software livre da Web 2.0, abriram um novo mundo de aplicações para utilização em boas práticas educativas. Um bom exemplo é o uso da timeline do Facebook para narrar uma cronologia (viagem, experiência, investigação, evento).

Para a pesquisadora Anna Ursyn (2014), os mitos, lendas e contos tradicionais começam a ser transportados para ambientes online. A intensa potencialidade que os meios de comunicação operam na atualidade trouxe com a internet, algumas caracterizações diferenciadas para a forma como são estabelecidas as interações entre pessoas e plataformas digitais. Esse contato com as formas tradicionais da imagem, do som e do verbo ganham, na internet, contornos mais interativos, onde as tecnologias, que permitem a visualização das coisas, são operadas tanto por quem produz como por quem recebe as mensagens. Essa interação dinâmica muda o antigo status da comunicação que deixava emissores, receptores e produtores isolados e atuando dentro do processo comunicativo de formas diferenciadas.

Todos estes mitos tradicionais, lendas, contos de fadas, contos, parábolas e fábulas tem encontrado o seu lugar nas técnicas de storytelling da comunicação multimídia atual, então o modelo storytelling digital poderia assumir a antiga arte em atuais modos de expressão. As tecnologias de visualização atuais combinam histórias com os formatos multimídia, como texto, imagens, som e movimento com narrativas, comentários e descrições em um ambiente dinâmico e interativo muitas vezes, de modo que o espectador torna-se o co-criador da arte. Os espectadores usam powerpoint, flickr, movie maker, fotos digitais e vídeos, para tratar de questões e desafios, enriquecer informações, evocam respostas e envolvem emocionalmente as pessoas, servindo para produzir notícias, marketing, aplicativos, educacional e de treinamento para as empresas. (Ursyn, 2014, p. 440)

A autora apresenta essas relações apontando que nos cenários contemporâneos há uma combinação de formas narrativas com tecnologias multimídia, o que desponta uma maior interatividade por meio da participação das pessoas, no sentido de criarem materiais em diferentes formatos que podem ser publicados, visualizados e comentados. 
Percebe-se que a internet revolucionou a forma como os conteúdos são apresentados, pois possibilitou uma certa democratização nos conteúdos oferecidos, antes rígidos e controlados por sistemas de grandes empresas comunicacionais.

Nesse sentido, os próprios meios de comunicação começaram a perceber a demanda existente na potencialidade interativa da internet e estruturaram caminhos conectivos entre eles. Surge assim um complexo fluxo de interatividades, pontuadas por Henry Jenkins (2008) no livro Cultura da Convergência. Jenkins estabelece vários conceitos para estes novos contextos estabelecendo a ideia de narrativa transmídia, que se atem a esse cenário de propagação de conteúdos que se deslocam em diferentes canais. Narrativa transmídia não é simplesmente a projeção de conteúdos em diferentes meios, como uma transposição e sim um deslocamento narrativo entre conteúdos projetados em diferentes plataformas de comunicação (Rodrigues \& Bidarra, 2016).

É importante perceber que nestes deslocamentos, as narrativas se moldam, encaixando-se em diferentes formatos e arranjos. É comum hoje serem oferecidos cursos sobre storytelling, pois este conceito é visto como tendência em ambientes de negócios, sociais, publicitários e também relacionado a questões educacionais e outros. Segundo Anna Ursyn (2013), o storytelling visual introduz uma quarta dimensão, pois possibilita um vagar temporal e espacial para seguir as peripécias dos personagens criados. Os personagens, na tela do computador, transmitem emoções, realismo, sentimentos que são percebidos pela audiência. Neste sentido, ganha espaço a arte digital, que desenvolve técnicas e poéticas, a fim de construir possíveis narrativas visuais em ambientes de interação.

Brian Alexander (2011) traduz o conceito de digital storytellling, estabelecendo várias características e situando definições em consonância com o próprio desenvolvimento da internet. Primeiramente, o autor estabelece um questionamento importante: como pode uma história existir fora do tempo, além da atemporalidade? É bem verdade que as narrativas lineares foram centrais na construção de aspectos de nossa História, Artes, Literatura, etc. e mesmo nos meios de comunicação produtos como as novelas, filmes e vídeos tendem para a construção ordenada de narrativas. Estas sempre dialogaram com as grandes audiências.

No cinema fomos letrados por um sistema narrativo clássico, promovido por Hollywood. A narrativa bem estruturada em seus elementos mais ordenadores e rígidos, ganhou projeção e destaque com os grandes filmes americanos, que sustentaram até hoje, um modelo padronizado de apresentação dos componentes estruturais de uma narrativa em harmonia com aspectos de uma produção audiovisual de caráter mais transparente. Bruce Block (2010, p. 233) discute que as narrativas se estruturam em três partes principais: a exposição, o conflito e a resolução. Percebe-se que a exposição se atem a apresentação dos fatos para o desenrolar da história; o conflito é o ponto ápice, o momento do clímax e a resolução o término da narrativa. Portanto, o cinema americano organiza suas narrativas bem próximas deste modelo e pode ser visto como um grande referencial das narrativas audiovisuais, pois nestes aproximadamente cento e vinte anos de sua existência, confirma-se um legado de histórias das mais diversas contadas e recontadas por meio das narrativas fílmicas. 
Tratando de videoclipes, como apontado anteriormente, o contar histórias torna-se um pouco mais complexo diante de algumas considerações importantes, tais como: o tempo da música, o caráter publicitário de divulgação da canção, da imagem do artista e também da performance do artista que pode assumir a persona de um personagem dentro de uma narrativa ou fazer o papel de apresentação e interpretação da música. A linguagem do videoclipe é ágil, rápida, calcada eminentemente em arranjos rítmicos, quer rápidos ou lentos. É necessário visualizar a correspondência entre os arranjos rítmicos das canções com as imagens visuais. Recentemente, a cantora pop Lana del Rey foi protagonista de um filme de curta metragem chamado Trópico, onde três das canções de seu álbum são incorporadas a um contexto único. Lana representa uma personagem com performances musicais, atuações e muito simbolismo. Assinado como um filme para ambientes online, Trópico possui trinta minutos e pode ser assistido inteiramente ou também fragmentado em três partes distintas relacionados diretamente com as canções temáticas.

O fato acima evidencia que a linguagem do videoclipe é muito envolvente, tendo sido incorporada a linguagem da internet também, promovendo arranjos que se conectam com as características específicas dos meios digitais e de redes. Percebemos que grande parte dos novos videoclipes são apresentados com a intenção de se contar histórias. É neste sentido que procuramos estabelecer a relação com o storytelling, pouco discutido especificamente quando a ênfase são os videoclipes.

Bryan Alexander estabelece pontuações históricas sobre o desenvolvimento do conceito de digital storytelling. $\mathrm{O}$ autor desenvolve seu pensamento a partir do progresso da própria internet e seu avanço tecnológico. Denominado a partir de ondas, o crescimento foi tão rápido e vertiginoso que despontou variadas formas de interatividade a partir do momento que surgiram as plataformas online. A nova onda do storytelling digital é defendida por Alexander (2001) a partir do surgimento da Web 2.0.

Sites da Web 2.0, em contrapartida, permitem que múltiplos canais de comunicação entre os visitantes do site, os criadores do site e de outras partes. Eles são fundamentalmente destinados a incentivar tais conexões por meio de edição wiki, lista de comentários, a inclusão de mídias, marcações, Facebook, serviços Digg e Reddit, e muito mais. Os visitantes de um site pode deixar comentários ou adicionar marcas, ou conectar-se a ele a partir de seu próprio site. Outros visitantes podem ver esses comentários e outras conexões, como um convidado da festa que entram em uma sala onde uma conversa está em pleno andamento. Vários usuários podem construir objetos e coleções em conjunto, a partir de uma página wiki e acrescentar uma foto de uma piscina compartilhada para a imagem Gliffy, desenhada em conjunto. (Alexander, 2011, p. 31)

Apesar do caráter de efemeridade das mensagens projetadas nos ambientes online, blogs, Twitter, Facebook, entre outros, despertaram uma explosão de conteúdos, por meio da participação das pessoas. Assim, nesse arsenal, algumas histórias saltam, 
ganham projeção e são invadidas, tornando-se alvo de discussões e polêmicas. Esse é o caráter da "viralização". Ser "viral" é interessante, pois diante de uma diversidade de formas e acontecimentos, a viralização é a aparição, a sobreposição, a amplificação, garantindo um impacto em termos de audiência. Segundo Bryan Alexander, o digital storytelling combina elementos sequenciais, e essa sequencialidade dos acontecimentos é o fator essencial para a compreensão dessas novas narrativas.

Sequência é importante por outra razão, a saber, a importância de extensão das histórias no tempo. Uma imagem, objeto ou tom musical único, normalmente, não constitui uma história. São peças de histórias, mídias soltas aguardando o seu uso. Agora, uma audiência pode transformar um único item em uma história através do processo de recepção. (Alexander, 2011, p. 13)

Como apontado por Alexander (2011), uma simples fotografia não desponta narrativas por ela mesma. Ela precisa ser introduzida num tempo, numa associação lógica com outras plasticidades. Para se criar narrativas, é necessário ferramentas e a internet oferece várias delas. Criar fotos, manipular as imagens, introduzir textos, aplicar um emoticon num comentário, são alguns dos vários exemplos. Nas mídias audiovisuais surgem os vídeos interativos, possibilidades de integração e produção de materiais audiovisuais democraticamente. Por outro lado, quando discutimos a linguagem do videoclipe falamos de uma ampliação da potencialidade de se contar histórias. De fato, isso sempre ocorreu nos contornos da linguagem do videoclipe de forma pouco acentuada, mas o que caracterizava a linguagem do videoclipe era a descontinuidade narrativa.

Indo na contramão da tendência da fragmentação, pensamos que o storytelling em videoclipes se conecta a uma associação com os elementos chave da construção de uma narrativa como tempo, espaço, dramatização, personagens, ações, diálogos e outros. Um dos princípios fundamentais e que facilita a leitura e o entendimento das narrativas em videoclipes, é justamente, o da sequencialidade cujos limites ultrapassam os determinados pelo tempo exato da canção. Há possibilidades para quebras, pausas, interações entre os personagens e esses recursos ordenam o tempo e o espaço fílmico. $O$ YouTube tem um papel importante neste processo, pois será a plataforma de mídia online que irá, de certa forma, moldar essas novas potências da linguagem do audiovisual.

\section{YouTubE COMO PLATAFORMA DE DIFUSÃo}

Um dos aspectos mais importantes da produção audiovisual é a distribuição, que deve ser pensada estrategicamente. Antigamente, as projeções cinematográficas e audiovisuais tinham caminhos estruturados numa ordenação bastante lógica: projeções em cinemas, televisores, fitas magnéticas e até mesmo em museus. Como afirmado anteriormente, numa lógica cada qual com suas funções bem amarradas. Nas novas mídias, a participação da audiência é, certamente, uma das maiores novidades. Como vem sendo apontado por vários especialistas, estamos vivenciando momento de interatividade em altas proporções. Por outro lado, a distribuição opera de formas diferenciadas. 
Henry Jenkins (2014) apresenta as dificuldades que as corporações de mídias online possuem para assegurar a legalidade da projeção e dos direitos autorais. Esses novos esquemas são importantes, pois apresentam-se de uma maneira mais democrática. A plataforma YouTube, sem dúvidas, é o meio de projeção audiovisual mais famoso da atualidade. Sua interface é de fácil acessibilidade e interatividade. Além de uma infinidade de materiais audiovisuais a disposição, você pode também fazer parte com ser perfil e publicar vídeos particulares ou simplesmente criar listas de preferências, disponibilizadas a todos.

Jean Burges e Joshua Green (2009) enfatizam a natureza de promoção de aspectos sociais relacionados ao cotidiano, que permitem a exposição do ser privado no YouTube. Ficou mais democrático ver um material audiovisual e mais acessível a oferta também, pois cada um participa ora contemplando, ora promovendo e ora se tornando a própria mensagem message (Burgess \& Green, 2009).

Além do fato, já bastante evidenciado, da possibilidade que o YouTube apresenta de promover a interação do público de uma forma em que as pessoas possam publicar seus comentários, vídeos e materiais e expor suas próprias experiências. Também se concretizou como uma mídia com canais específicos para a projeção de videoclipes, um dos mais famosos é o canal Vevo, que na verdade é um site de entretenimento que, por meio de uma parceria, desloca seus conteúdos para o YouTube.

Essa nova modalidade de visualização destitui a MTV de um centro referencial na projeção de videoclipes. A emissora fechou suas portas em alguns países e, atualmente não tem o mesmo alcance frente as recepções como havia no passado. Entendemos que o canal MTV, por apresentar um fluxo de mensagens muito condicionado aos blocos da publicidade, limitava processos criativos no sentido de abertura para narrativas, pois o tempo exato da canção era um condicionante para o encaixe também na programação. Apesar de que, na história do videoclipe, houve sempre algumas representações que fugiram a essas regras, como, por exemplo, o emblemático videoclipe Thriller, de Michael Jackson. A partir de fontes do livro de Alexander (2011), em média dois bilhões de usuários assistem a vídeos diariamente por meio do YouTube. É provável que, atualmente, essa proporção tenha aumentado, principalmente com a evolução na aquisição de telefonia móvel. Hoje, vemos uma nova manifestação de trânsito entre as mídias online, dos tradicionais computadores para os tablets, celulares e dispositivos de natureza móvel.

Nicholas Rombes (2009) discute como o cinema se molda a partir dos procedimentos de natureza digitais. O autor apresenta uma série de particularidades que caracterizam as manifestações digitais na natureza da imagem audiovisual. Uma delas é essa alteração do status das grandes telas para uma diminuição de formatos. Rombes (2009, p. 120) argumenta que o fator sedutor da imagem cinematográfica visualizada em grandes formatos de telas passa por um campo de transformação, o que altera a forma como recebemos as imagens.

O encolhimento de filmes para pequenas telas que são portáteis apaga todas as sugestões remanescentes de mistificação: não há mistérios para 
filmes de hoje. De certa forma, isto está de acordo com o projeto iniciado pela arte minimalista uma simplicidade tão intensa que se torna quase ornamentado. Pequenos, telas portáteis não pode deixar de revelar os contornos da sua produção: ao contrário da tela do cinema, não há algo ruim que circunda tela de vídeo do portátil: telas de cinemas portáteis permitem que o cinema siga-nos em todos os lugares. (Rombes, 2009, p. 120)

Para o autor, isso não pode ser visto de maneira negativa, pois apesar do status minimalista desta alteração na forma como a imagem é projetada, a sua atuação estará sempre em movimento, o que faz com que a imagem se potencialize na frequência de exposição. Pensamos que a projeção estabelecida em pequenos formatos desqualifica a questão que envolve a qualidade da imagem e apreensão perceptiva de quem recebe.

Visto por essa lógica, a plataforma YouTube permite uma interatividade entre usuários e materiais audiovisuais. Estabelecida em pequenos formatos, tal apropriação se dá ao contato bastante particular. Esta recepção é transitória, fluida e vinculada a intensiva fragmentação de imagens e sons.

\section{NARRATIVAS DILATADAS EM VIDEOCLIPES}

Ao propor este estudo, pensamos que nos ambientes online, por mais que os vídeos e filmes tendem para apresentações rápidas, fragmentadas e dinâmicas, estamos verificando tendências que vão na contramão. Uma dessas se atém a verificação de que vários videoclipes contemporâneos ampliam o tempo da música e centram a parte imagética em narrativas bem definidas, o que chamamos de narrativas dilatadas. É comum a utilização de um prólogo que demarca características iniciais narrativas. David Bordwell (2005) desenvolve um estudo sobre as particularidades dos processos narrativos estabelecidos no cinema americano clássico. Segundo o autor, há um conjunto de estruturas marcantes nos estudos narrativos literários, que se apresentam como componentes das narrativas cinematográficas. Tais particularidades se aproximam de um cinema que prioriza a dramatização centrada nos princípios da linearidade e sequencialidade (Bordwell, 2005).

Bordwell sinaliza as várias possibilidades de estudos da narrativa vinculadas ao cinema, a partir de caracterizações estruturalistas, conteudistas e de apreensão da recepção. Isso é importante, pois demarca princípios de estudos dos componentes narrativos de um filme, cujo ponto central da discussão do autor se atém ao fato de que na narração clássica, o espectador constrói um tempo e espaço da fábula com coerência e clareza.

Bruce Block (2010, p. 233), ao estudar a narrativa visual, apresenta uma ligação importante entre a estrutura da visualidade e os componentes estruturais de uma narrativa, que são: a exposição, o conflito e a resolução. Block entende a exposição como o início da história. O conflito como o momento chave da narrativa, o que impulsiona a história. Um conflito pode ser interno (do personagem) ou externo (ligado a uma situação). A resolução é o momento em que o público precisa para refletir sobre o conflito da narrativa ou seja é o final da história (Block, 2010). 
Para o autor a narrativa e a exposição visual devem ser reveladas ao mesmo tempo. $\mathrm{Na}$ exposição devem ser criadas estratégias visuais que demarcam as caracterizações importantes de espaços, personagens e situações. Porém, no momento da apresentação do conflito, tais marcas devem ser realçadas, aumentando o contraste cria-se uma percepção de maior intensidade. Na resolução, segue-se a linha de afinidade, estabelecendo relações de menor intensidade visual.

Andre Gaudreault (2009) aponta questionamentos para a definição da narrativa cinematográfica. Segundo o autor, duas características são importantes de se compreender para o entendimento de como se apresentam as narrativas cinematográficas, são elas: a mostração fílmica e a mostração cênica. Ambas dimensionam o local onde as histórias são contadas nos filmes. A primeira deve-se aos elementos essenciais da linguagem cinematográfica, estabelecidos por meio das configurações dos planos, da imagem, da composição e dos elementos de cores, entre outros. A mostração cênica incorpora as atuações e dramatizações de personagens, vistos pela ação e atuação deles no espaço e no tempo.

Torna-se importante discutir estas considerações, na tentativa de pensar como a narrativa é estabelecida na linguagem do videoclipe. Vernalis (2004. p. 13) discute que as narrativas em videoclipes são disjuntivas, ou seja não há uma conexão entre letra, imagens e a música. Segundo a autora, o videoclipe tende a criar uma sensação de história, mas que não se completa.

Ao estabelecer o conceito de "narrativas dilatadas" (Oliva, 2017) argumentamos que existe uma ampliação na forma como as narrativas dos videoclipes são apresentadas. Como dito acima, é comum a presença de um prólogo sem a música, com apresentação de personagens, ações, caracterizações, inclusão de falas e diálogos. Podemos associar a questão da exposição visual e narrativa de Bruce Block. Ao iniciar a música, uma série de artimanhas de composição fílmica podem ser usadas a partir das configurações das linguagens audiovisuais sincronizadas ao ritmo musical e imagético. Nos videoclipes contemporâneos, as performances das personagens não estão condicionadas ao tempo exato da música, pois existe a possibilidade de inserção de diálogos incorporados ou não à canção. Estabelece-se um clímax nas situações narrativas com um resolução sem a música, geralmente ao finalizar o videoclipe.

Neste sentido, no cenário contemporâneo, verifica-se que esta estratégia discursiva é utilizada com recorrência (Barboza, 2015). Se outrora a linguagem do videoclipe se caracterizava pela desconstrução da narrativa, o que vemos atualmente é uma ampliação deste tipo de forma para os videoclipes. Penso que esta caracterização deve-se essencialmente às novas plataformas midiáticas, que permitem uma recepção diferente daquela imposta pelos cânones específicos da exposição de videoclipes na televisão.

\section{AnÁLISE DE CASOS}

Propomos para este estudo, uma análise de dois videoclipes dirigidos pelo cineasta canadense Xavier Dolan. Ambos os videoclipes contam histórias e apresentam uma 
narrativa com os parâmetros que designamos como "narrativas dilatadas". O primeiro chama-se Hello e evidencia a protagonista como a própria cantora da música, que atua como personagem e intérprete ao mesmo tempo. Trata-se da cantora inglesa Adele. $\mathrm{O}$ segundo dispensa a banda e se apresenta somente por meio de personagens sem a participação da banda francesa Indochine.

O videoclipe da canção Hello inicia com um prólogo sem a música tema. Neste momento somos apresentados a uma situação. O primeiro plano é uma imagem desfocada de uma janela. Vemos um plano aberto pela moldura da janela e ao fundo, em perspectiva, um carro se aproximando. Adele fala ao telefone: "I've just got here, and I think I'm losing signal already. Hello? Can you hear me now? Sorry. I'm sorry, I'm sorry". Não sabemos com quem ela está falando, mas é certo que existe uma situação-chave. $A$ personagem diz que está em um lugar, mas que está perdendo o sinal e pede desculpas por algo. Estabelece nesse prólogo um caráter narrativo: apresentação de uma personagem, situação enigmática com a imagem do carro e na fala da personagem a perda do sinal e o pedido de desculpas.

A cor do videoclipe é sépia, o que já indica uma situação de indiferença. O prólogo finaliza com imagens da protagonista retirando lençóis de um mobiliário. Esses planos representam que o local está um pouco abandonado, o que é bastante significativo para a compreensão da narrativa do filme. Em seguida, vemos um close-up de Adele, onde ela faz movimentos com o pescoço como se estivesse cansada e em, seguida, olha diretamente para a câmera, atendo o seu olhar para o espectador. Neste momento, ouvimos a canção e a cantora faz a performance dizendo Hello!

Neste momento inicial de apresentação da música, vemos uma série de planos de detalhe mostrando a personagem fazendo coisas domésticas, como o café da manhã, verificando anotações e falando ao telefone. Sincronizado a essas imagens, vemos a projeção em subjetiva de um segundo personagem, um homem jovem e negro. Toda a abordagem deste personagem é feito no recurso da câmera subjetiva como se o personagem olhasse diretamente para a personagem/cantora. Essas situações nos são apresentadas no cotidiano da casa, porém em duas abordagens, uma inicialmente demonstrando uma certa harmonia entre o casal e posteriormente, apresentando um conflito, com brigas e situações mais dramáticas. Em um dos momentos, por exemplo, o personagem é mostrado cenicamente embaixo de chuva. Essas imagens do rapaz são apresentadas por meio de flashbacks temporais incorporados a narrativa fílmica.

Um dos pontos interessantes deste videoclipe é o recurso dos diálogos que não são mostrados nitidamente. Ouvimos ruídos que ficam sonoramente abaixo da música. Os ruídos de falas evidenciam e possibilitam o entendimento narrativo da situação, pois por mais que não temos o conteúdo da fala, entendemos o arranjo do discurso, estabelecido pela relação e atuação do casal.

No videoclipe haverá um espaço narrativo fora do contexto da história do casal, estabelecido por meio da representação telefônica coberta por trepadeiras, evidenciando um abandono. A performance da cantora se estabelecerá neste espaço externo, uma espécie de floresta com folhas secas num estilo meio outonal. Neste momento deslocado 
da narrativa provoca-se uma amplitude por meio da interpretação e dramatização que Adele faz com a canção.

O clímax é revelado de maneira muito rápida quase no final com a resolução. Vemos uma imagem da personagem próxima a janela. No ambiente externo, o rapaz está próximo da casa, fechando o porta-malas do carro e também o celular. A personagem aparece na janela. Essa cena potencializa a narrativa, pois estabelece uma conexão com o prólogo do videoclipe, porém nos abre a possibilidade de uma interpretação ambígua, pois fica complexo entender a questão temporal do videoclipe, pois a primeira cena mostra um carro chegando a casa, após um plano detalhe da janela.

O que é importante verificar neste videoclipe é que os personagens bem como suas ações são apresentados numa forma em que conseguimos evidenciar uma história, sendo esta contada com princípios bem determinados. A narrativa é ampliada por meio de estratégias que permitem situar os personagens em tempo presente e passado, e espaços que identificam a estrutura básica de uma história.
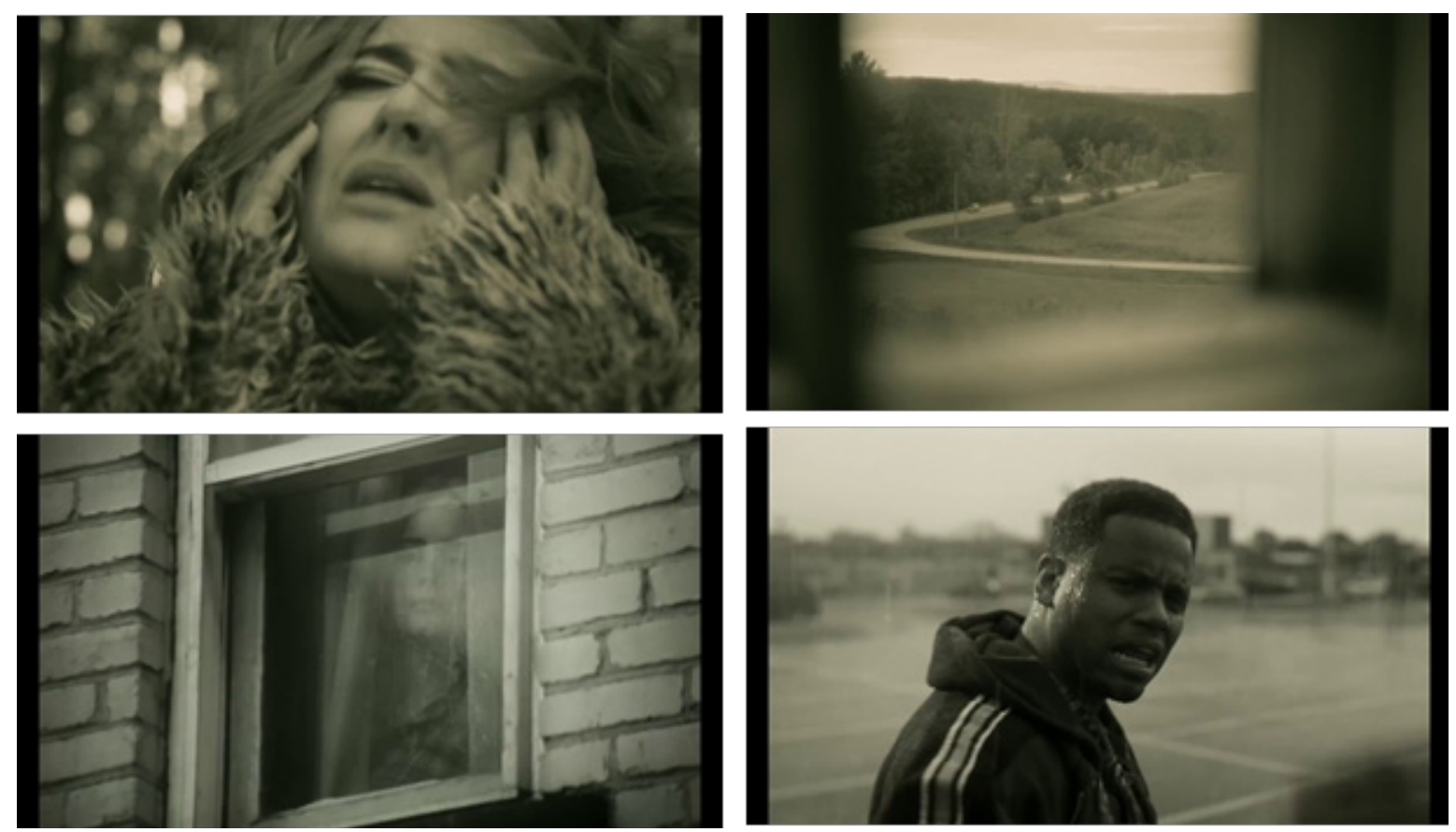

Figura 1: Frames do videoclipe da música Hello! da cantora Adèle, dirigido por Xavier Dolan, 2015 Fonte: https://www.youtube.com/watch?v=YQHsXMgICgA

O videoclipe College Boy possui o mesmo esquema narrativo do videoclipe Hello! Filmado no formato 1:1 com as bordas laterais pretas. O filme também tem um prólogo sem o tema musical. Vemos o personagem principal, neste caso não há nenhuma participação dos integrantes da banda Indochine. O local apresentado inicialmente é uma sala de aula, em total silêncio, pois a professora escreve algumas informações no quadro negro. O personagem está sentado em sua cadeira enquanto olha para o caderno. Vemos uma série de enquadramentos dos outros alunos com closes de amassar de papel e, em seguida, uma situação um tanto quanto exagerada, quando vários alunos jogam 
papéis no jovem. Uma caneta cai no chão e quebra o silêncio. A professora escuta o barulho, porém se mantém na mesma postura. Ela não reage ao ocorrido. Esse plano da professora será importante para o entendimento da história do filme. Vemos um close no rosto do personagem com um liquido escorrendo de algo que foi arremessado sobre ele. Em seguida, toca o sinal que indica o término da aula. Nesse prólogo, a câmera se apresentará em slow motion, caracterizando um aspecto visual do videoclipe todo e demarcará um personagem antagonista: um dos garotos estudantes que será apresentado com destaque pela movimentação lenta da câmera e ataque de papéis ao personagem principal.

O filme é todo em preto e branco com aspectos voltados para o cinza. Há um caráter de indiferença no filme, pois todos os personagens estão mascarados perante a violência estabelecida com o garoto. O prólogo será finalizado com o som do sinal que a aula foi finalizada. A partir do plano detalhe no sinalizador, começamos a ouvir a canção.

A partir do início da música, a marginalização do personagem principal será evidenciada, pois veremos uma imagem dele caminhando pelos corredores da escola até o local onde fica o seu armário. Veremos que o armário está todo danificado e o personagem pegará um espelho quebrado. A câmera faz um close e vemos a imagem do personagem projetada no espelho quebrado. Em seguida, mostra uma perseguição, onde vemos somente o jovem fugindo de algo em slow motion.

Na sequência, é apresentada uma série de cenas rápidas como se fossem flashbacks: o personagem num jantar com a família evidenciando um certo desconforto dele para com as ações dos familiares à mesa; o personagem dentro do seu quarto dando socos e o personagem num jogo de basquete fazendo uma cesta e se tornando alvo de chacota de seus colegas. Neste momento alguns personagens já são apresentados com olhos vedados por lenços. Essa representação demarca a apatia dos personagens no sentido de defendê-lo dos personagens algozes.

Volta-se ao tempo da narrativa referente à perseguição e são mostrados vários de planos de violência e maltrato feitos para com o garoto. Esses personagens cometem a violência e são mostrados sem os lenços nos olhos enquanto os outros assistem a cena com as olhos vedados. A exposição do videoclipe é feita de várias cenas que enaltecem a violência até o momento da crucificação da personagem principal. O diretor polemiza tudo nesta imagem, pois os rapazes atiram com armas de fogo no personagem crucificado. Ao som de um chamado, todos voltam para a escola deixando-o sozinho. A resolução é finalizada com o cessar da música e o olhar do personagem para a câmera em contre-plongèe, quando ele diz obrigado em francês.

College Boy é um videoclipe totalmente narrativo. O fato de não ter participação da banda, não permite uma sinalização com outro tempo e espaço narrativo. As cenas são todas amarradas a uma situação especifica, o fílmico será composto por meio de uma estratégia linear, incrementada com pequenos flashbacks. Essa situação parte do inicio na sala de aula até a hora do recreio e retorno para a sala de aula. Neste desenrolar temporal e espacial, vemos a exposição da violência e os debates temáticos que sobressaem destas armações da narrativa. 
Verifica-se que nos dois trabalhos dirigidos por Xavier Dolan se estabelece um estilo de representação narrativa bem definido. A dilatação da narrativa é conseguida por meio de arranjos rápidos, porém eles desarmam categorias especificas da linguagem do videoclipe, quando pensados a partir de uma desconstrução narrativa. Pensamos que o contar histórias não se perde no atual cenário das mídias, pois é evidente a ampliação dos recursos narrativos em audiovisuais.
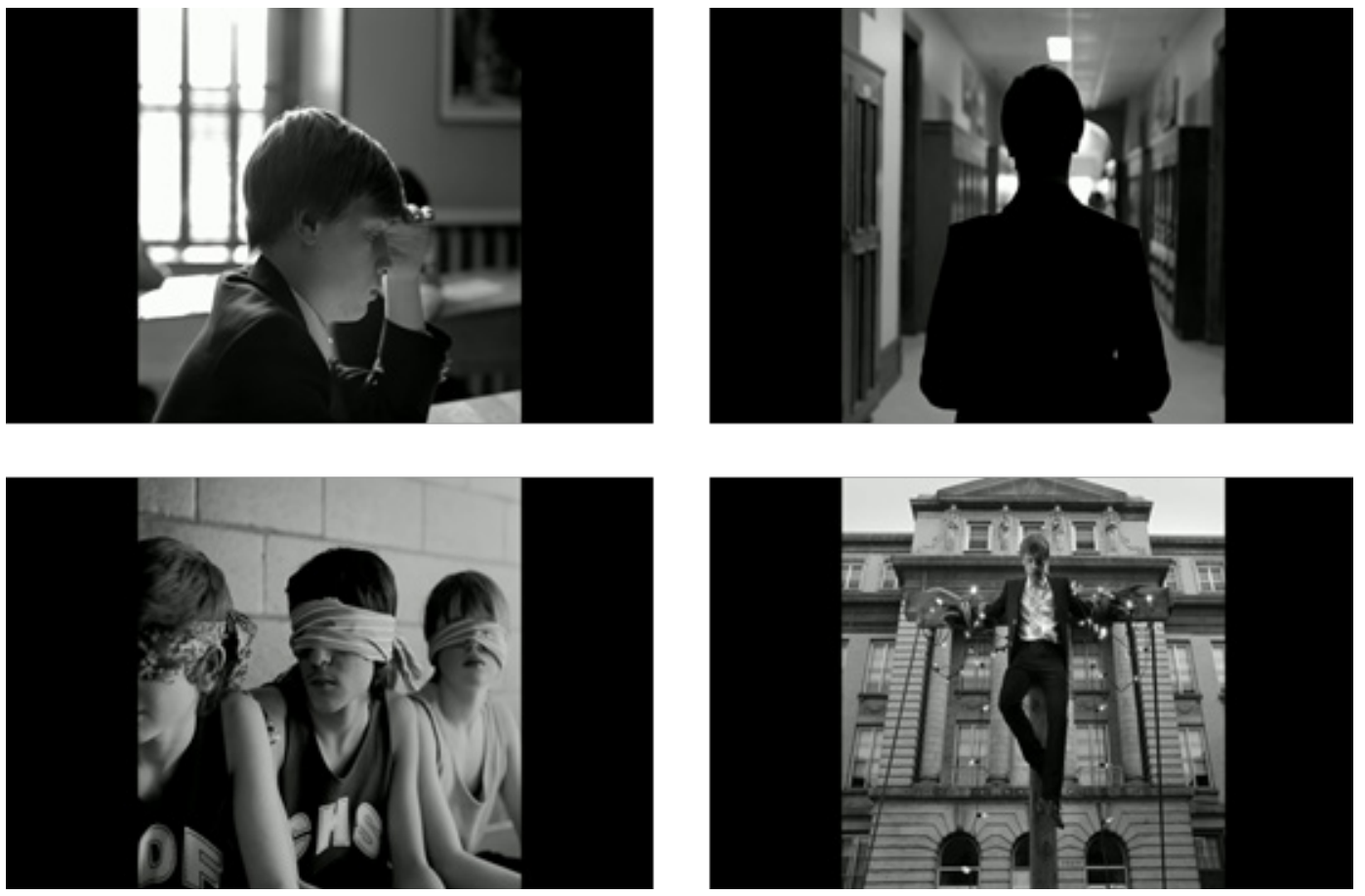

Figura 2: Frames do videoclipe da música College Boy, Indochine, dirigido por Xavier Dolan, 2013 Fonte: https://www.youtube.com/watch?v=Rp5U5mdARgY

\section{ConclusÃo}

Neste trabalho mostrámos como, nos contornos das mídias convergentes, a forma de apreensão dos materiais produzidos se molda a partir de novas formulações. Traçámos um olhar para aspectos da narratividade em audiovisuais do nosso mundo digital, centrados na linguagem do videoclipe, a partir de um pensamento que vem sendo discutido nos últimos anos, devido a sua articulação com os processos contemporâneos da imagem e do som.

Digital storytelling é visto como um princípio para a compreensão da inserção narrativa em variados formatos audiovisuais atuais. Vimos nos videoclipes analisados que a sequencialidade misturada a presença de personagens e ações, visualizados em espaços e tempos fragmentados, dinamizam formas de se compreender a presença das narrativas. É notável na plataforma online YouTube, por exemplo, uma significativa tendência para videoclipes que apelam para o desenvolvimento de estruturas narrativas próximas a postulação clássica da narrativa cinematográfica, quando vistas pela ordenação lógica e clara dos princípios que regem a estrutura de uma história. 
Se o que caraterizou a linguagem do videoclipe foi a intensa experimentação e desconstrução narrativa, verifica-se atualmente uma ampliação de possibilidades, cujo desenvolvimento de estratégias não mais se limitam ao tempo exato da canção. Designamos de "narrativas dilatadas" a evidente ampliação narrativa decorrente destas novas transposições midiáticas.

Existe finalmente a percepção de que a aplicação das tecnologias digitais começa a traduzir-se em resultados efetivos e globais. Estes resultados não se limitam a meras situações experimentais como até aqui, existem tendências e vias de progresso evidentes: o controle passou para o usuário, os materiais "cinematográficos" cederam lugar aos recursos digitais, a informação passou a estar disponível online em vez de offline, e as atividades tornaram-se sessões interativas partilhadas em comunidades. Mas, talvez mais importante, os usuários passaram a ser produtores de materiais multimídia, detentores de informação sempre atualizada e incansáveis comunicadores, em permanente mobilidade.

Num cenário futuro, vemos um novo perfil de espectadores de imagens audiovisuais, não mais ligados a velhos e grandes formatos, mas visualizando em pequenas e móveis telas. Pensamos que existirá sempre um local para se contar histórias, por mais que esta ampliação pareça contrapor-se, ainda assim o contar histórias se faz presente entre os seres humanos.

\section{REFERÊNCIAS BIBLIOGRÁFICAS}

Alexander, B. (2011). The new digital storytelling: creating narratives with new medias. Santa Bárbara: Praeger.

Barboza, E. M. R. (2015). Narrativas digitais: um estudo sobre os videoclipes interativos da banda Arcade Fire. Comunicação e Sociedade, 27, 369-385. doi: 10.17231/comsoc.27(2015).2107.

Bellour, R. (1997). Entre-imagens: foto, cinema e vídeo. Campinas: Papirus.

Block, B. (2010). A narrativa visual: criando a estrutura visual para o cinema, TV e mídias digitais. São Paulo: Elsevier.

Bordwell, D. (2005). O cinema clássico hollywoodiano: normas e princípios narrativas. In F. P. Ramos (Ed.), Teoria Contemporânea do Cinema: documentário e narratividade ficcional (pp. 278-279). São Paulo: SENAC.

Brandão, D. (2010). Cultura participativa. Resenha crítica sobre a obra Convergence Culture - Where Old and New Media Collide; de Henry Jenkins. Revista Comunicação e Sociedade, 18, 245-256. Retirado de http:// revistacomsoc.pt/index.php/comsoc/article/view/1004/969

Burgess, J. \& Green, J. (2009). YouTube e a revolução digital: como o maior fenômeno da cultura participativa transformou a mídia e a sociedade. São Paulo: Aleph.

Gaudreault, A., Jost, F. (2009). A narrativa cinematográfica. Brasilia: Editora Universidade de Brasilia.

Jenkins, H. (2014). Cultura da conexão. São Paulo: Aleph.

Jenkins, H. (2008). Cultura da convergência. São Paulo: Aleph.

Oliva, R. (2015). Por uma estética da hiperestilização: Interconexões de poéticas audiovisuais. Tese de Doutoramento, Universidade Tuiuti do Paraná, Paraná, Brasil. 
Oliva, R. (2017). Interconexões de poéticas audiovisuais. Curitiba: Appris.

Rodrigues, P. \& Bidarra, J. (2016). Transmedia storytelling as an educational strategy: a prototype for learning English as a second language. International Journal of Creative Interfaces and Computer Graphics (IJCICG): [Special Issue on the ARTECH 2015 International Conference], 7(2), 55-66.

Rombes, N. (2009). Cinema in the Digital Age. Londres: Wallflower.

Sousa, M. N.; Zagalo, N. \& Martins, M. (2012). "Eu Também Posso Propagar Histórias". A Adaptação e as Narrativas Transmediáticas na Era da Participação. Comunicação e Sociedade, 22, 167-183. doi: 10.17231/ comsoc.22(2012).1280

Vernallis, C. (2004). Experiencing music video: aesthetics and cultural context. Nova Iorque: Columbia University Press.

Vernallis, C. (2013). Unruly media: YouTube, music video and the new digital cinema. Nova lorque: Oxford University Press.

Ursyn, A. (2014). Visual and verbal storytelling, In A. Ursyn (Eds.), Computational Solutions for Knowledge, Art, and Entertainment: Information Exchange Beyond Text (pp. 429-455). Hershey PA, USA: IGI Global. doi: $10.4018 / 978-1-4666-4627-8 . c h 022$

Wolske, J. (2014). Interactive torytelling and experiental learning: the prospect of "vertical narrativity". In F. M. M. Neto (Eds.), Technology Platform Innovations and Forthcoming Trends in Ubiquitous Learning (pp. 194214). Hershey PA, USA: IGI Global. doi: 10.4018/978-1-4666-4542-4.cho11

\section{NotAS BiográFicAS}

Rodrigo Oliva é Doutor em Comunicação e Linguagens pelo Programa de Pós-graduação em Comunicação e Linguagens da Universidade Tuiuti do Paraná (2016). Mestre em Comunicação: Mídia e Cultura pela Universidade de Marília (2005). Especialista em Práxis e Discurso Fotográfico pela Universidade Estadual de Londrina (2001). Graduado em Comunicação Social com habilitação em Cinema pela Fundação Armando Alvares Penteado (2000). Professor Titular do Curso de Comunicação Social - Publicidade e Propaganda da Universidade Paranaense. Tem experiência docente em cursos na área da Comunicação: história, estética das mídias, marketing, cinema, televisão, vídeo e em práticas e leituras textuais.

E-mail: prof.rodrigo.oliva@gmail.com

Universidade Paranaense, Praça Mascarenhas de Moraes, s/n, 87502-080 Umuarama, Brasil

José Bidarra é doutorado em Ciências da Educação, é Professor na Universidade Aberta, lecionando no Departamento de Ciência e Tecnologia. É coordenador da Secção de Informática, Física e Tecnologia (SIFT). Foi co-autor do modelo virtual pedagógico usado pela Universidade Aberta. Os seus interesses de pesquisa focam-se do multimédia e dos média digitais na educação à distância, o que inclui e-books, jogos e simulações. As suas atividades de investigação têm lugar na Universidade Aberta e no Centro de Investigação em Artes e Comunicação (CIAC), da Universidade do Algarve. 
E-mail: jose.bidarra@uab.pt

Departamento de Ciências e Tecnologia, Universidade Aberta, Rua da Escola Politécnica, 141, 1269-001 Lisboa, Portugal

Denize Araujo possui Pós-Doutorado em Cinema pela UAlg - Universidade do Algarve, Portugal, Doutoramento em Literatura Comparada, Cinema e Artes pela UCR-University of California, Riverside (EUA) e Mestrado em Cinema e Artes pela ASU - Arizona State University (EUA). É Coordenadora da Pós-Graduação em Cinema, Supervisora de Pós-Doutorado e Docente do Mestrado e Doutorado em Comunicação e Linguagens da Universidade Tuiuti do Paraná. É membro do Conselho Internacional, do Comitê de Publicação e da Comissão de Normas e vice-coordenadora do GT de Cultura Visual da IAMCR. É Curadora do FICBIC - Festival de Cinema da Bienal Internacional de Arte de Curitiba. Pesquisa nas áreas de Arte e Comunicação.

E-mail: denizearaujo@hotmail.com

Universidade Tuiuti do Paraná - Rua Sydnei Antonio Rangel Santos, 238 - Santo Inacio, Curitiba - PR, 82010-330, Brasil

* Submetido: 19-08-2017

* Aceite: 03-11-2017 